\title{
Patients satisfaction with laboratory services at antiretroviral therapy clinics in public hospitals, Addis Ababa, Ethiopia
}

Tedla Mindaye $e^{1}$ and Bineyam Taye $e^{1,2^{*}}$

\begin{abstract}
Background: Despite the fact that Ethiopia has scale up antiretroviral treatment (ART) program, little is known about the patient satisfaction with ART monitoring laboratory services in health facilities. We therefore aimed to assess patient satisfaction with laboratory services at ART clinics in public hospitals.

Methods: Hospital based, descriptive cross sectional study was conducted from October to November 2010 among clients attending in nine public hospitals ART clinics in Addis Ababa Ethiopia. Patients' satisfaction towards laboratory services was assessed using exit interview structured questionnaire. Data were coded and entered using EPI info 2002 (Centers for Disease Control and Prevention Atlanta, GA) and analyzed using SPSS version 15 software (SPSS INC, Chicago, IL, USA).

Results: A total of 406 clients were involved in the study. Of these 255(62.8\%) were females. The overall satisfaction rate for ART monitoring laboratory services was (85.5\%). Patients were satisfied with measures taken by health care providers to keep confidentiality and ability of the person drawing blood to answer question ( $98.3 \%$ and $96.3 \%$ respectively). Moreover, the finding of this study revealed, statistical significant associations between the overall patients' satisfaction with waiting time to get blood drawing service, availability of ordered laboratory tests and waiting time to get laboratory result with $(p<0.05)$. Patients receiving blood drawing service less than 30 minute were 7.59 times (95\% Cl AOR: 3.92-14.70) to be more satisfied with ART monitoring laboratory services compared to those who underwent for more than 30 minutes.
\end{abstract}

Conclusions: Overall, the satisfaction survey showed, most respondents were satisfied with ART monitoring laboratory services. However, factors such as improving accessibility and availability of latrines should be taken into consideration in order to improve the overall satisfaction.

Keywords: Patient satisfaction, ART, Laboratory services, Ethiopia

\section{Background}

Patient satisfaction is the patient's perception of care received compared with the care expected [1]. Evaluating to what extent patients are satisfied with health services is clinically relevant, as satisfied patients are more likely to comply with treatment [2], take an active role in their own care [3], continue using medical care services and

\footnotetext{
* Correspondence: bineymt@yahoo.com

${ }^{1}$ College of Health Science, School of Clinical laboratory Science, Addis Ababa University, Addis Ababa, Ethiopia

${ }^{2}$ College of Health Science, School of public health, Addis Ababa University, Addis Ababa, Ethiopia
}

stay within a health provider (where there are some choices) and maintain with a specific system [2]. On the other hand clients who are not satisfied with a service may have worse outcomes than others because they miss more appointments, live against advice or fail to follow through on treatment plans.

In clinical laboratory monitoring patients satisfaction is an important and useful tools required for quality improvement as well as to maintain their accreditation $[4,5]$.

Antiretroviral treatment (ART) monitoring laboratory services have crucial roles in delivery of quality of ART

\section{Biomed Central}


by diagnosing and staging HIV infection [6]. However, comprehensive quality laboratory services are a challenging process; need multiple sources of supports from clients, providers, managers, and other stakeholders. Especially, needs and preferences of clients in clinical laboratory must be addressed in the design and implementation of laboratory quality system. Disregard for patients' feedback may cause persistent disruption of testing because a patient has to return several times for the results and treatment. Thus monitoring patient satisfaction is an important and useful quality improvement indicator and is required by clinical laboratories [4].

The literature indicates that there are only a few reports of patients' satisfaction from developing countries, as compared to the high volume of publications on patients' satisfaction from developed countries [7,8]. In Ethiopia, most patients' satisfaction survey are carried out in general health service either outpatient or inpatient departments [9-12]. However, to our knowledge there is no study conducted particularly in ART monitoring laboratory services.

Therefore, this study was designed to assess patient satisfaction to ward ART monitoring laboratory services in public hospitals of Addis Ababa, Ethiopia.

\section{Methods}

\section{Study setting and context}

Hospital based, descriptive cross sectional study was conducted between October and November 2010. The study was conducted in Addis Ababa which is the capital city of Ethiopia. Addis Ababa has a population size of $2,738,248$ million with annual growth rate of 2.1 [13]. The city is divided into ten sub-cities and 99 kebeles (Lowest level administrative unit in the city). This study focused on nine public hospitals which have been providing antiretroviral treatment services for people living with HIV/AIDS (PLWHA). The hospitals were Tikur Anbessa specialized teaching hospital, St. Peters TB specialized hospital, ALERT, St. Paul, Zewditu Memorial, Yekatit 12, Minilik II, Ras Desta Damtew, and Ghandi memorial hospitals.

The client load of ART clinics in each hospital according to the Federal HIV/AIDS Prevention and Control Office (FHAPCO) monthly HIV care and ART update as of February, 2010 was 2619 for Tikur Anbessa specialized teaching hospital, 1769 St. Peters TB specialized 4945 ALERT, 3170 St. Paul, 5685 Zewditu Memorial, 2146 Yekatit 12, 1758 Minilik II, 1008 Ras Desta Damtew, and 238 Ghandi memorial hospitals [14]. Each hospital has a separate laboratory units specifically designed to serve only HIV infected patients enrolled in ART clinic and perform laboratory tests used to monitoring ART follow up. The service render in these laboratories are ART monitoring tests including clinical chemistry (liver and renal function tests), hematology (Complete
Blood Count, CD4 count) and other laboratory tests used for the management of HIV infected taking ART. Patients visit laboratory every 3 months and had proper counseling about drug adherence and laboratory test used for monitoring their treatment.

\section{Study subjects}

Adult PLWHA ( $>18$ years of age) who visited ART clinics for at least three months and referred to ART clinics laboratory for ART monitoring laboratory tests including clinical chemistry (liver and renal function), Hematology (Complete Blood Count, CD4 count) and were not confused or too ill to participate.

\section{Sample size and sampling producer}

The sample size was estimated based on the assumption that $50 \%$ of the patients attending in ART clinic laboratories are satisfied, a $5 \%$ margin of error, and a $95 \%$ confidence level $(\mathrm{P}=50 \%$ was taken due to absence of reliable previous study that show patents satisfaction ART monitoring laboratory service in Ethiopia). The initial sample size was 384 however, considering $10 \%$ non response rate the final sample size was 422 .

The sample size in each public hospital was subsequently determined according to the proportion of the client load of ART clinics in each hospital after reviewing the monthly HIV care and ART update as of February, 2010 by FHAPCO/MOH [14]. Adult patients were randomly selected from those attending ART clinics in each hospital using ART clinic registration books as the sampling frame for selection of patients.

\section{Measurement and data collection}

The data was collected via face-to-face interviews, in which the translated Patients' Satisfaction Questionnaire in Amharic was used to guide the researcher. All interviews were carried out by one of the investigators to standardize interviews and reduce interview biases.

The questionnaire contains of satisfaction indicators which are related to socio-demographic characteristics of the patients and different dimensions of ART monitoring laboratory services such as waiting time, availability of requested laboratory tests, needle stick attempt, information provision about bruise, availability of space in blood drawing room, privacy, respect and courtesy, confidentiality.

Standardized 5-point Likert scales ranging from strongly disagree to strongly agree (1 to 5 points) were used for all items. Patients' satisfaction were classified; into two categories satisfied and dissatisfied by using the demarcation threshold from formula: \{(total highest score-total lowest score)/2\} + Total lowest score [15]. 


\section{Statistical analysis}

Data were coded and entered using EPI info 2002 (Centre for Disease Control and Prevention Atlanta, GA) and analyzed using SPSS version 15 software (SPSS INC, Chicago, IL, USA). Descriptive statistics were computed to ascertain the percentage of patient Satisfaction in each satisfaction indicators. Binary and multiple logistic regressions were subsequently conducted to predict the factors which influence the level of satisfaction with ART monitoring laboratory services. P-Value less than 0.05 were taken as statistically significant.

\section{Ethical consideration}

Before any attempt to collect data, approval to conduct the study was obtained from Institutional Review Board (IRB) of School of Medicine, Addis Abba University. Each participant (patient) was notified about the purpose of the study, the right to refuse to participate in the study, and anonymity and confidentiality of the information gathered. They were assured that they would not be penalized for not participating if they wished not to participate, and that their responses to the questions would have no effect on their care.

\section{Results}

A total of 422 respondents were selected as the sample of the study. However, 16 respondents (3.8\%) refused to participate, and hence, 406 clients of the antiretroviral clinics in nine public hospitals were interviewed in this study. The response rate derived in this study was $96.2 \%$.

Based on the result of this study that majority of respondents were females $255(62.8 \%)$, age group 28-37 204(50.2\%); with family monthly income 500-1000 Ethiopian Birr (1ET.Birr =17.2USD). Also, this table showed that most of the respondents had attended at least secondary school education 208(51.2\%) and employee of private sectors $140(34.5 \%)$ (Table 1 ).

\section{Level of satisfaction of clients with laboratory service}

The result regarding respondents' satisfaction with different dimensions of ART monitoring laboratory services are presented in Table 2. Generally, most of the respondents were satisfied with the providers' courtesy/respect 382(94.1\%), cleanliness of blood drawing area 386 (95.6\%), measures taken by health care providers to keep confidentiality 399(98.3\%), completeness of information when and how client receive laboratory results 376 (92.6\%), ability of the person drawing blood to answer questions 391(96.3\%) and comfort of chairs in blood drawing room $361(88.1 \%)$. On the other hand most of the clients showed low satisfaction level with latrine cleanness and comfort 257(63.5.0\%), accessibility and availability of latrines $262(64.5 \%)$.
Table 1 Socio demographic characteristics of patients of Antiretroviral Treatment service in the public hospitals, in Addis Ababa, December, 2010 ( $n=406$ )

\begin{tabular}{|c|c|c|}
\hline Variable & Number & Percentage (\%) \\
\hline \multicolumn{3}{|l|}{ Sex } \\
\hline Male & 151 & $37.2 \%$ \\
\hline Female & 255 & $62.8 \%$ \\
\hline Total & 406 & $100.0 \%$ \\
\hline \multicolumn{3}{|l|}{ Age } \\
\hline $18-27$ & 46 & $11.3 \%$ \\
\hline $28-37$ & 204 & $50.2 \%$ \\
\hline $38-47$ & 96 & $23.6 \%$ \\
\hline $48-57$ & 44 & $10.8 \%$ \\
\hline $58 \&$ above & 16 & $3.9 \%$ \\
\hline Total & 406 & $100.0 \%$ \\
\hline \multicolumn{3}{|l|}{ Marital status } \\
\hline Single & 110 & $27.1 \%$ \\
\hline Married & 151 & $37.2 \%$ \\
\hline Divorced & 63 & $15.5 \%$ \\
\hline Widowed & 82 & $20.2 \%$ \\
\hline Total & 406 & $100.0 \%$ \\
\hline \multicolumn{3}{|l|}{ Religion } \\
\hline Orthodox & 312 & $76.8 \%$ \\
\hline Muslim & 38 & $9.4 \%$ \\
\hline protestant & 54 & $13.3 \%$ \\
\hline Others & 1 & $0.2 \%$ \\
\hline no answer & 1 & $0.2 \%$ \\
\hline Total & 406 & $100.0 \%$ \\
\hline \multicolumn{3}{|l|}{ Educational status } \\
\hline Illiterate & 36 & $8.9 \%$ \\
\hline Read and write & 42 & $10.3 \%$ \\
\hline Primary school(1-8) & 73 & $18.0 \%$ \\
\hline Secondary school completed & 208 & $51.2 \%$ \\
\hline College & 47 & $11.6 \%$ \\
\hline Total & 406 & $100.0 \%$ \\
\hline \multicolumn{3}{|l|}{ Occupation } \\
\hline Student & 10 & $2.5 \%$ \\
\hline Government employee & 68 & $16.7 \%$ \\
\hline Private employee & 140 & $34.5 \%$ \\
\hline Daily laborer & 46 & $11.3 \%$ \\
\hline Merchant & 24 & $5.9 \%$ \\
\hline Housewife & 45 & $11.1 \%$ \\
\hline Unemployed & 73 & $18.0 \%$ \\
\hline Total & 406 & $100.0 \%$ \\
\hline \multicolumn{3}{|l|}{ Income class in Eth Birr ${ }^{1}$} \\
\hline Less than 150 & 98 & $24.1 \%$ \\
\hline $150-499$ & 71 & $17.5 \%$ \\
\hline
\end{tabular}


Table 1 Socio demographic characteristics of patients of Antiretroviral Treatment service in the public hospitals, in Addis Ababa, December, 2010 ( $n=406)$ (Continued)

\begin{tabular}{lll}
\hline $500-1000$ & 141 & $34.7 \%$ \\
over 1000 & 49 & $12.1 \%$ \\
Non response & 47 & $11.6 \%$ \\
Total & 406 & $100.0 \%$ \\
\hline
\end{tabular}

${ }^{1}$ Eth Birr equivalent to 17.2 USD.

In overall, a vast majority of the respondents 347 (85.5\%) were satisfied with ART monitoring laboratory service received at nine public hospital in Addis Ababa (Table 2).

The relationship between the patients' level of satisfaction and independent variables

The chi-square of independence was conducted to assess whether the level of patients' satisfaction had a relationship with explanatory variables.

The results from the cross-tabulations analysis showed that there were no significant relationship between gender, Educational background, marital status, occupational status, and family monthly income with level of patients' satisfaction toward ART monitoring laboratory services $(\mathrm{P}$ value $>0.05)$. However, there were significant relationship between age group with level of patients' satisfaction $\left(x^{2}=8.10, \mathrm{df}=3, \mathrm{p}=0.04, \mathrm{n}=344\right)$. Furthermore, there was significant relationship between availability of

Table 2 Level of satisfaction of clients of ART clinic in the public hospitals of Addis Ababa, December, 2010 ( $n=406)$

\begin{tabular}{lll}
\hline & \multicolumn{2}{c}{ Level of Satisfaction } \\
\cline { 2 - 3 } Variables & Number & $\%$ \\
\hline Privacy during blood drawing & 362 & 89.2 \\
Cleanliness of blood drawing area & 386 & 95.6 \\
Respect and courtesy & 382 & 94.1 \\
$\begin{array}{l}\text { Ability of Person drawing blood to put } \\
\text { client at ease }\end{array}$ & 382 & 94.1 \\
Comfort of chairs & 361 & \\
Completeness of information on how & 376 & 88.9 \\
and when to receive lab result & & 92.6 \\
Ability of the person drawing blood to & 391 & \\
answer question & & 96.3 \\
Latrine accessibility and availability & 262 & 64.5 \\
Latrine cleanness and comfort & 257 & 63.5 \\
Cleanness and comfort of waiting area & 363 & 89.4 \\
Confidentiality measure & 399 & 98.3 \\
Overall service satisfaction * & 347 & 85.5 \\
\hline
\end{tabular}

* Based on this formula (Total highest score-total lowest score)/2\} + Total lowest score), satisfaction level threshold was set at the score $>33$. place for blood drawing room to put things, Information provision about bruise, availability of lab tests, Waiting time to get blood drawing service and laboratory results with level patients' satisfaction toward ART monitoring laboratory service $(P$ value $<0.05)$ (Table 3 ).

\section{Factors affecting the level of clients' satisfaction}

In univarate analysis, overall satisfaction of clients toward ART monitoring laboratory services showed statistically significant association with waiting time to get blood drawing service, availability of place in blood drawing room to put client personal things, provision of information regarding bruise due to blood drawing, availability of ordered laboratory tests $(\mathrm{p}<0.05)$.

When adjusted odds ratios were calculated statistical significant associations were found between the overall satisfaction of the clients with waiting time to get blood drawing service, availability of ordered laboratory tests and waiting time to get laboratory result with $(\mathrm{p}<0.05)$.

Results of multiple logistic regression analysis showed that clients who waited less than 30 minutes to get blood drawing services were 7.5 times more likely to be satisfied than those who waited more than 30 minutes (AOR =7.59: CI: 3.92-14.70). Moreover those clients who waited less than two hours to get laboratory results were five times more likely to be satisfied than those who waited more than two hours (AOR $=5.52$; CI: $1.58-$ 19.23) and clients who got all requested laboratory tests were 2.3 times likely to be satisfied than those who did not got the information $(\mathrm{AOR}=2.36 ; \mathrm{CI}: 1.26-4.44$ ) (Table 4).

\section{Discussion}

This study has revealed that overall client satisfaction level with the ART monitoring laboratory services were $85.5 \%$ that showed a vast majority of the respondents were satisfied with almost all aspects of ART monitoring laboratory services they received. The results reported here could be explained in several ways. One explanation is that the structure of the questionnaire was limited in indicating underlying factors. On the other hand, the high satisfaction could be due to introduction of social desirability biases by clients. Clients might not be ready to tell their dissatisfaction status freely since the interviews were carried out within the hospitals. Again, it should be remembered that, unless special precautions are taken, clients may be reluctant to reveal their opinions for fear of alienating their attendants as ART monitoring laboratory services are given free of charge [3]. A similar study conducted by Akhtari-Zavare $\mathrm{M}$ et al. in government teaching hospitals in Tehran, they found that $82 \%$ of these patients were satisfied [16].

The result of the present study has also showed higher patient satisfaction rate than the reports by other 
Table 3 Relationship between level of Patients' satisfaction with independent variable $(n=406)$

\begin{tabular}{|c|c|c|c|c|c|}
\hline Variables & $\begin{array}{l}\text { Satisfied } \\
\text { (n) }\end{array}$ & $\begin{array}{l}\text { Not } \\
\text { Satisfied (n) }\end{array}$ & $x^{2}$ & df & $\begin{array}{l}P \\
\text { value }\end{array}$ \\
\hline \multicolumn{6}{|l|}{ Gender } \\
\hline Male & 127 & 24 & 0.072 & 1 & \\
\hline Female & 217 & 38 & & & 0.788 \\
\hline \multicolumn{6}{|l|}{ Age Group } \\
\hline $18-27$ & 42 & 4 & & & \\
\hline $28-37$ & 163 & 40 & & & \\
\hline $38-47$ & 83 & 14 & 8.10 & 3 & \\
\hline $48-57$ & 56 & 4 & & & 0.04 \\
\hline \multicolumn{6}{|c|}{ Educational status } \\
\hline Illiterate & 34 & 2 & & & \\
\hline Read and write & 36 & 6 & 3.16 & 4 & \\
\hline $\begin{array}{l}\text { Primary school } \\
(1-8)\end{array}$ & 62 & 11 & & & 0.531 \\
\hline $\begin{array}{l}\text { Secondary } \\
\text { school } \\
\text { completed }\end{array}$ & 173 & 35 & & & \\
\hline Collage & 39 & 8 & & & \\
\hline \multicolumn{6}{|l|}{ Marital status } \\
\hline Single & 91 & 19 & & & \\
\hline Married & 130 & 21 & 1.08 & 3 & \\
\hline Divorced & 55 & 8 & & & 0.780 \\
\hline Widowed & 68 & 14 & & & \\
\hline \multicolumn{6}{|l|}{ Occupation } \\
\hline Unemployed & 178 & 33 & & & \\
\hline Employee & 166 & 29 & 0.046 & 1 & \\
\hline Income class & & & & & 0.891 \\
\hline Less than 150 & 85 & 13 & & & \\
\hline $150-499$ & 64 & 7 & 5.23 & 3 & \\
\hline 500-1000 & 118 & 23 & & & 0.155 \\
\hline over 1000 & 37 & 12 & & & \\
\hline \multicolumn{6}{|c|}{ Availability of place in blood drawing } \\
\hline Yes & 71 & 3 & & & \\
\hline No & 272 & 59 & 8.84 & 1 & \\
\hline \multicolumn{5}{|c|}{ Information provision about bruise } & 0.00 \\
\hline Yes & 180 & 20 & & & \\
\hline No & 164 & 42 & 7.68 & 1 & \\
\hline \multicolumn{3}{|c|}{ Availability of lab tests } & & & 0.00 \\
\hline Yes some only & 109 & 27 & & & \\
\hline Yes all & 233 & 35 & 12.9 & 1 & \\
\hline \multicolumn{5}{|c|}{ Waiting time to get blood drawing service } & 0.00 \\
\hline$<30$ minutes & 253 & 15 & & & \\
\hline $1 / 2-1$ hour & 36 & 10 & & & \\
\hline 1-2hours & 31 & 22 & 65.28 & 3 & \\
\hline$>2 \mathrm{hrs}$ & 24 & 15 & & & 0.00 \\
\hline
\end{tabular}

Table 3 Relationship between level of Patients' satisfaction with independent variable $(n=406)$ (Continued)

\begin{tabular}{|c|c|c|c|c|c|}
\hline \multicolumn{6}{|c|}{ No of Needle stick attempt } \\
\hline $\begin{array}{l}\text { One veni } \\
\text { puncture }\end{array}$ & 268 & 46 & & & \\
\hline $\begin{array}{l}\text { Two veni } \\
\text { puncture }\end{array}$ & 65 & 11 & 3.28 & 2 & \\
\hline $\begin{array}{l}\text { Three veni } \\
\text { puncture }\end{array}$ & 11 & 5 & & & 0.19 \\
\hline \multicolumn{6}{|c|}{ Waiting time to get lab result } \\
\hline$<1$ hours & 74 & 7 & & & \\
\hline $1-2$ hour & 27 & 10 & 18.2 & 2 & \\
\hline$>2$ hours & 243 & 45 & & & 0.00 \\
\hline
\end{tabular}

researchers in Ethiopia as shown $57.1 \%$ and $43.6 \%$, in Jimma and Tigray respectively $[17,18]$. The underlying justifications for higher clients' satisfaction with ART services than outpatient services in other areas include multiple factors. ART services in Ethiopia are focus of attentions for government and many donors. Different interventions of monitoring, reporting including policies and implementation guidelines are functional for ART services. Many Donors are investing on the program large amount of resources and give technical supports. Clients are also benefiting from improved quality of life, decreased morbidities and mortality due to ART.

Mfinanga SG et al. [19] reported that patients with higher education were more likely to be dissatisfied. On the contrary, results of this study showed that there was no relationship between the educational status of the patients and their overall satisfaction with ART monitoring laboratory service. This could be due to the fact that most of patients were completing only secondary school; hence there was no difference in their expectations.

The result of this study showed a significant relationship between waiting time to get blood drawing service and laboratory results with level patients' satisfaction toward ART monitoring laboratory service which is consistent with the study conducted in Amhara and Tigray region showing that long waiting hours were associated with dissatisfaction $[9,18]$.

Based on the findings, the patients receiving blood drawing service less than 30 minute were found to be more satisfied with the ART monitoring laboratory services compared to those who underwent for more than $30 \mathrm{~min}$ utes. The results of this study showed that there was a significant relationship between the level of satisfaction and the availability of the requested laboratory tests during their visit in the laboratory. One possible explanation for the significant finding is that patients who fail to get the requested laboratory tests at the time could have been 
Table 4 Predictor variables of the level of patients' satisfaction toward ART monitoring laboratory services

\begin{tabular}{|c|c|c|c|c|c|c|}
\hline \multirow[t]{2}{*}{ Variables } & \multicolumn{2}{|c|}{ Dependent Variable } & \multirow{2}{*}{$\begin{array}{l}\text { Crude odds ratio } \\
(95 \% \mathrm{Cl})\end{array}$} & \multirow{2}{*}{$\begin{array}{l}P \\
\text { value }\end{array}$} & \multirow{2}{*}{$\begin{array}{l}\text { Adjusted OR } \\
(95 \% \mathrm{Cl})\end{array}$} & \multirow{2}{*}{$\begin{array}{l}P \\
\text { value }\end{array}$} \\
\hline & ${ }^{1}$ Sat(n) & Not Sat.(n) & & & & \\
\hline \multicolumn{7}{|c|}{ Availability of place in blood drawing room to put things } \\
\hline No & 271 & 59 & 1 & & 1 & \\
\hline Yes & 71 & 3 & $5.13(1.56-16.8)^{*}$ & 0.007 & $2.02(0.56-7.34)$ & 0.282 \\
\hline \multicolumn{7}{|c|}{ Information provision about bruise } \\
\hline No & 164 & 42 & 1 & & 1 & \\
\hline Yes & 180 & 20 & $2.30(1.30-4.0)^{*}$ & 0.004 & $1.81(0.93-3.51)$ & 0.077 \\
\hline \multicolumn{7}{|l|}{ Availability of lab tests } \\
\hline Yes some only & 109 & 27 & 1 & & 1 & \\
\hline Yes all & 233 & 35 & $2.72(1.56-4.71)^{*}$ & 0.000 & $2.36(1.26-4.44)^{*}$ & 0.007 \\
\hline \multicolumn{7}{|c|}{ Waiting time to get blood drawing service } \\
\hline$>30$ minutes & 253 & 15 & 1 & & 1 & \\
\hline$<30$ minutes & 91 & 47 & $8.71(4.64-16.3)^{*}$ & 0.000 & $7.59(3.92-14.70)^{*}$ & 0.000 \\
\hline \multicolumn{7}{|c|}{ Number of Needle stick attempts } \\
\hline More than one attempts & 76 & 16 & 1 & & 1 & \\
\hline Only One attempt & 268 & 46 & $0.81(0.43-1.52)$ & 0.521 & $1.28(0.60-2.71)$ & 0.511 \\
\hline \multicolumn{7}{|c|}{ Waiting time to get lab result } \\
\hline$>2$ hours & 243 & 59 & 1 & & 1 & \\
\hline$<2$ hours & 101 & 3 & $8.17(2.50-26.60)^{*}$ & 0.000 & $5.52(1.58-19.23)^{*}$ & 0.007 \\
\hline
\end{tabular}

*Significant Associations as $\mathrm{P}<0.05,{ }^{1}$ Satisfaction.

forced to get the laboratory service at private facility with high costs. Such event usually happened when laboratory equipments such as CD4 machine could have been broken down; as a consequent, they had to wait for the hospitals to get the machine repaired.

Logistic regression showed that waiting time to get blood drawing service and waiting time to get laboratory results are the predictor for level of patients' satisfaction. This result is similar with the study conducted by Soleimanpour et al., on patients hospitalized at emergency department the results showed that; overall satisfaction rate was dependent on the mean waiting time [20].

\section{Limitation}

There are several limitations to the design of this study. One limitation is related to the selection bias. This was due to the fact that the participation in the study was based on voluntary basis, usually those voluntary are satisfied and don't have complain from ART monitoring laboratory services. Consequently increase the result of satisfaction from ART monitoring services. On the other hand, Clients of ART might give biased information since interview was conducted in the hospitals. Furthermore a sample of 406 patients is not big enough to detect any significant association between socio-demographic characteristics and level of patients' satisfaction.

\section{Conclusions}

Overall, the satisfaction survey showed that most respondents were satisfied with ART monitoring laboratory services. However, the respondents suggested that several factors such as improving accessibility and availability of latrines should be taken into consideration in order to improve the overall satisfaction.

Also, higher level of measure taken to keep confidentiality, ability of the person drawing blood to answer question and cleanliness of blood drawing area may increase patients' level of satisfaction towards ART monitoring laboratory services.

Finally, this study also showed that the patients, receiving blood drawing service less than 30 minute, were found to be more satisfied with the ART monitoring laboratory services compared to those who underwent for more than 30 minutes. Further improvement can also be achieved, if ART monitoring laboratories institutionalizing quality management system and using its feed back in a systematic way to enhance patient satisfaction with ART monitoring laboratory services.

\section{Competing interests}

All authors declare that they have no conflict of interest associated with the publication of this manuscript.

\section{Acknowledgements}

The study was funded by Addis Ababa University, School of Medical Laboratory science, Ethiopia. We would like to acknowledge study subject and participating laboratory staffs of each hospital for their administrative 
support and cooperation. We would also like to thank our senior colleague Dr Aster Tesgaye who critically commented the proposal of this research.

\section{Authors' contributions}

TM conceived and designed the study and collected data, performed analysis, Interpretation of data, and draft the manuscript. BT assisted with the design, performed analysis, interpretation of data and the critical review of the manuscript. All authors read and approved the final manuscript. All authors participated in critical appraisal and revision of the manuscript.

Received: 7 October 2011 Accepted: 20 April 2012

Published: 20 April 2012

\section{References}

1. Aiello A, Garman A, Morris BS: Patient satisfaction with nursing care: A multilevel analysis. J Quality Management in Health Care 2000, 312(3):187-191.

2. Marquis MS, Davies AR, Ware JE Jr: Patient satisfaction and change in medical care provider: a longitudinal study. Med Care 1983, 21:821-829.

3. Donabedian A: The quality of care. How can it be assessed? JAMA 1988, 260:1743-1748.

4. Joint Commission on Accreditation of Health care Organizations: Comprehensive Accreditation Manual for Pathology and Clinical Laboratory Services. Oakbrook Terrace, III: Joint Commission on Accreditation of Healthcare Organizations; 2005:PI.3.10

5. College of American Pathologists: Laboratory General Checklist: laboratory accreditation program. Northfeld, III: College of American Pathologists; 2005. GEN.20316,

6. Minanga SG, Kahwa A, Kimaro G, Kilale A, Kivuyo S, Senkoro M, et al: Dissatisfaction with laboratory service in conducting HIV related testing among public and private medical personnel in Tanzania. BMC Health Res Bull 2007, 9:110-114

7. Gadallah M, Zaki B, Rady M, Anwer W, Sallam I: Patient satisfaction with primary health care services in two districts in lower and upper Egypt. Comparative study. East Mediterr Health J 2003, 9:422-430.

8. Bernhart MH, Wiadnyana IGP, Wihardjo H, Pohan I: Patient satisfaction in developing countries. Soc Sci Med 1999, 48:989-996.

9. Mitike G, Mekonnen A, Osman M: Satisfaction on outpatient services in hospitals of the Amhara region. Ethiop Med J 2002, 40:387-395.

10. Dejene D: Assessment of Quality of Antiretroviral Treatment services in public hospitals of Addis Ababa [MPH thesis]. Addis Ababa University; 2008.

11. Getenet H, Hailemlak A, Tegegn A: Clients' satisfaction with Antiretroviral Therapy services at Jimma University Specialized Hospital. Ethiop J Health Sci 2008, 18:17-24.

12. Abraha A: Assesment of quality of antiretroviral therapy in governmental hospitals of Addis Ababa: with special focus on client satisfaction, perceived quality of life and adherence. [MPH thesis]. Addis Ababa University; 2007

13. Central Statistical Agency of Ethiopia (CSA): Summary and statistical report of the 2007 population and housing census. Addis Ababa: December 2008.

14. FMOH/FHAPCO: Monthly HIV care and ART updates. Addis Ababa, Ethiopia: February 2010

15. Pitaloka D, Rizal AM: Patients' satisfaction in antenatal clinic hospital Universiti Kembangaan Malaysia. J Community Health 2006, 12:8-16.

16. Akhtari-Zavare M, Abdullah MY, Said SB, Kamali M: Patient Satisfaction: Evaluating Nursing Care for Patients Hospitalized with Cancer in Tehran Teaching Hospitals, Iran. Global J Health Sci 2010, 2(1):117-126.

17. Olijera L, Gebresilasses $\mathrm{S}$ : Satisfaction with outpatient health services at Jimma hospital, South West Ethiopia. Ethiop J Health Dev 2001, 15(3):179-184

18. Adane G: Assessment of client satisfaction in outpatient department of zonal hospital of Tigray, Ethiopia. [MPH thesis]. Addis Ababa University; 2006. 2001; 15:179-184.

19. Minanga SG, Kahwa A, Kimaro G, Kilale A, Kivuyo S, Senkoro M, et al: Patient's dissatisfaction with the public and private laboratory services in conducting HIV related testing in Tanzania. BMC Health Serv Res 2008, 8:121-125.

20. Soleimanpour H, Gholipouri C, Salarilak S, Raoufi P, Vahidi RG, et al: Emergency department patient satisfaction survey in Imam Reza Hospital. Tabriz Iran. Int J Emer Med 2011, 4:2.

doi:10.1186/1756-0500-5-184

Cite this article as: Mindaye and Taye: Patients satisfaction with laboratory services at antiretroviral therapy clinics in public hospitals, Addis Ababa, Ethiopia. BMC Research Notes 2012 5:184.

\section{Submit your next manuscript to BioMed Central and take full advantage of:}

- Convenient online submission

- Thorough peer review

- No space constraints or color figure charges

- Immediate publication on acceptance

- Inclusion in PubMed, CAS, Scopus and Google Scholar

- Research which is freely available for redistribution 